\title{
Risk Assessment Based on Combined Weighting-Cloud Model of Tunnel Construction
}

\author{
Jing-chun WANG*, Jia-qi LIU, Qiang WEI, Peng WANG
}

\begin{abstract}
In order to reduce the tunnel construction accidents and ensure the safety of personnel, a comprehensive assessment method of tunnel construction risk based on combination weighting and cloud model is constructed according to the characteristics of tunnel construction. The risk assessment index system is established based on researches on engineering geological condition, natural environmental condition, Tunnel engineering design scheme and construction management. On this basis, the tunnel risk is divided into 4 levels and the index risk level standard is proposed. In order to improve the rationality of weighting, a weight calculation method based on AHP, entropy method and Lagrange multiplier method is constructed. Finally, the normal cloud generator is used to form comparison pictures of risk clouds and standard clouds, which demonstrates the risk status of the evaluation indexes at all levels. With reference to Deda Tunnel of Sichuan-Tibet Railway engineering of high integrated risk level, management decision-making is required. The evaluation results are basically consistent with engineering practices, proving that the method has good feasibility and applicability.
\end{abstract}

Keywords: cloud model; combination weight; risk assessment; tunnel construction

\section{INTRODUCTION}

Railway is the backbone of the comprehensive transportation system. With the in-depth advancement of the "One Belt, One Road" strategy, China has vigorously accelerated the pace of railway construction. Due to the complex structure and difficult construction technology of railway tunnel engineering, the risk factors in the construction process are intertwined and complicated. Tunnel construction projects in the complex and dangerous areas, represented by the Sichuan-Tibet Railway, are confronted with geological hazards such as collapse, landslide, debris flow, inrush of clay and water, high ground temperature, rock bursts, and large deformations of soft rocks from deep-buried tunnels $[1,2]$. The proportion of tunnels on the entire Sichuan-Tibet Railway is relatively high and there are many ultra-long and deep buried tunnels, so safety accidents are prone to occur during construction [3]. Therefore, in order to ensure the high-standard and high-quality safe construction of tunnel engineering, it is necessary to conduct risk analysis of tunnel construction, so as to avoid risks, improve risk management and control capability, and achieve the purpose of reducing accidents and casualties.

Modern risk management is generally acknowledged to have originated in Germany. In 1987, Sorrill of the UK first proposed the concept of risk engineering [4]. He believed that risk assessment should consider the common influence of multiple factors. After that, Einstein introduced the risk theory into tunnel engineering and studied the risk assessment theory of tunnel construction from the perspective of risk management [5]. Risk assessment methods have been widely used in the construction of tunnels and other underground projects [6]. Hyun et al [7] considered the impact of risk probability and used FTA and AHP to evaluate and analyze the construction risk of shield tunnel. Hadi et al. [8] used FAHP to analyze and evaluate the uncertain factors during the tunnel construction. Marian [9] demonstrates that Bayesian Belief Networks (BBNs) can be used as D-DSM to assess and manage risks and finally select best response decisions. Andreotti [10] used a comprehensive numerical method to evaluate the seismic risk of mountain tunnels and demonstrated it with two cases. Bjelland, H. \& Aven,
T. [11] assessed the risks of the undersea tunnel and provided ideas on how to assess the uncertain risks. Clarke, J. A. \& Laefer, D. F. [12] proposed a holistic risk assessment method before construction in view of the ground settlement that may be caused by tunnel construction. McFeat-Smith, I. \& Harman, K. W. [13] proposed a risk assessment system consisting of 33 risk types based on the risk analysis of more than 50 tunnels in Asia. Nezarat et al. [14] used FAHP to evaluate and classify the geological risks of tunnels, and sorted them out. In addition, Bayesian network method [15-17], FAHP [18], FNA [19], etc., has also been applied in the risk assessment of tunnel construction.

Cloud model can realize the bidirectional uncertainty mapping from evaluation value to evaluation domain, measure the fuzziness and randomness of evaluation index, and realize the conversion between qualitative concept and quantitative expression. Risk assessment methods based on cloud model have been applied in many fields [20-22]. Wu, H. W. [23] used cloud model and improved evaluation method to construct the second-level index system of urban rail transit operation safety evaluation, which provided reference and theoretical basis for urban rail transit operation safety planning and management. W. Dong [24] used the cloud model mixed entropy method - AHP to determine the weight, and finally determined the result after repeated simulation. The result showed that the evaluation result of the evaluation method based on the cloud model was better than other evaluation methods. Ma, X. Y. [25] applied the cloud model method to realize the multi-criterion assessment of rock fall risk in a tunnel portal section, and provided practical guidance for tunnel safety construction of similar projects.

Cloud model has been applied and developed to deal with the fuzziness and randomness of various indexes to a certain extent. Applying cloud model to the risk assessment of tunnel construction is beneficial to improve the accuracy of the assessment results. In order to solve the limitation of single subjective or objective weighting, the risk assessment results were further optimized, and the evaluation method based on the combined weighting cloud model was proposed, so as to provide decision-making suggestions for the risk level evaluation of tunnel construction. 


\section{BASIC THEORY OF CLOUD MODEL}

On the basis of traditional fuzzy mathematics theory and probability statistics, Academician Li Deyi proposed the uncertainty conversion model between qualitative concepts and quantitative values the cloud model. The cloud model mainly reflects the vagueness and randomness of the concept of uncertainty, and integrates the two together to form a qualitative and quantitative mutual mapping. The cloud model has universal adaptability and is applied to decision analysis, risk assessment, image processing and other fields.

Set $U$ as the universe of concrete numbers, $X$ as a qualitative concept of $U$. If the quantitative value $x \in U$, and $x$ is a random implementation of the qualitative concept $X$, where $y=U X_{(x)}$ is the degree of certainty of $x$ to $X$ and $U X_{(x)} \in(0,1)$, then the distribution of $x$ on the universe $U$ is called the cloud model.

Expectation Ex, entropy En, and excess entropy $\mathrm{He}$ are three indicators that reflect the digital characteristics of the cloud model, as shown in Fig. 1. Ex represents the central distribution position of cloud droplets in the space of the argument domain, which reflects the stability and unity of the cognition of a certain qualitative concept, and can most directly reflect the qualitative characteristics of the evaluation object. Entropy En represents the dispersion degree of cloud droplet, which reflects the degree of ambiguity of qualitative concept. The higher entropy is, the more obvious uncertainty is. Excess entropy $\mathrm{He}$ is the entropy of entropy, representing the dispersion degree of entropy, which is intuitively expressed as the thickness of cloud [26].

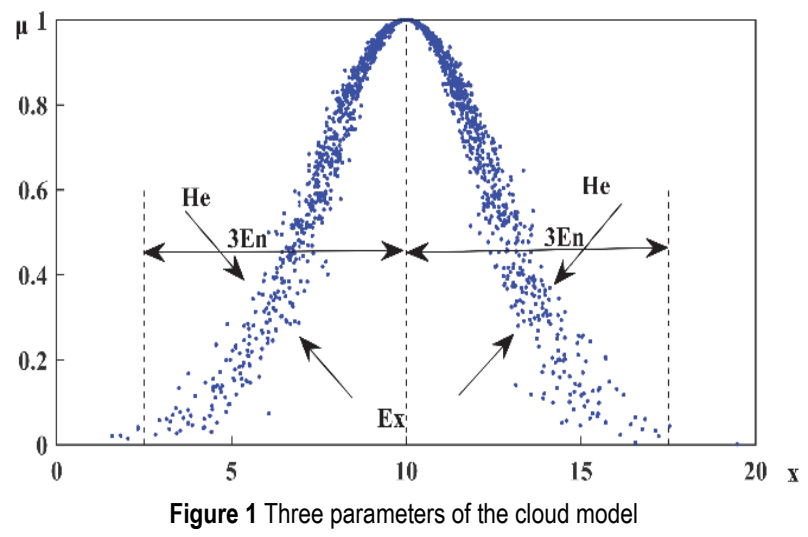

$$
\left\{\begin{array}{l}
E x=\frac{1}{q} \sum_{k=1}^{q} x_{k} \\
E n=\sqrt{\frac{\pi}{2}} \times \frac{1}{q} \sum_{k=1}^{q}\left|x_{k}-E x\right| \\
H e=\sqrt{\left|S^{2}-E n^{2}\right|} \\
S^{2}=\frac{1}{q-1} \sum_{k=1}^{q}\left(x_{k}-E x\right)^{2}
\end{array}\right.
$$

The cloud model achieves qualitative and quantitative conversion through two cloud generators. A certain number of cloud drops can be calculated by the forward cloud generator, and the three digital characteristics of the cloud can be determined by the reverse cloud generator $(E x, E n, H e)$. The specific calculation method is shown in Eq. (1), [27].

Where, $q$ is the number of samples; $x_{k}$ is the score value of the No. $k$ expert; $S^{2}$ is the sample variance.

\section{RISK ASSESSMENT MODEL OF TUNNEL CONSTRUCTION}

\subsection{Index System for Assessment of Tunnel Construction Risk}

The influencing factors of tunnel construction accidents are complex and diverse. In order to fully consider the information that characterizes the safety status of tunnel construction and the interrelationship of factors affecting construction risk, follow the principles of science, completeness, and hierarchy. From engineering geology, natural environmental conditions, tunnels engineering design plan and construction management technical level are studied, and establish the tunnel construction evaluation index system shown in Tab. 1.

Table 1 Risk assessment index system for tunnel construction

\begin{tabular}{|c|c|}
\hline First-level index & Second-level index \\
\hline \multirow{4}{*}{ Engineering geology $U_{1}$} & Basic quality grade of rock mass $U_{11}$ \\
\hline & Underground seepage volume $U_{12}$ \\
\hline & Rock weathering degree $U_{13}$ \\
\hline & Fault fracture zone situation $U_{14}$ \\
\hline \multirow{2}{*}{$\begin{array}{l}\text { Natural environmental } \\
\text { conditions } U_{2}\end{array}$} & Earthquake intensity $U_{21}$ \\
\hline & Annual rainfall $U_{22}$ \\
\hline \multirow{2}{*}{$\begin{array}{l}\text { Tunnel engineering Design } \\
\text { scheme } U_{3}\end{array}$} & Tunnel depth $U_{31}$ \\
\hline & Tunnel span $U_{32}$ \\
\hline \multirow{4}{*}{$\begin{array}{l}\text { Construction Management and } \\
\text { Technology } U_{4}\end{array}$} & Measurement Scheme $U_{41}$ \\
\hline & Emergency rescue level $U_{42}$ \\
\hline & Disturbance of surrounding rock $U_{43}$ \\
\hline & Effect of the support scheme $U_{44}$ \\
\hline
\end{tabular}

\subsection{Classification of Risk Levels}

Combining the characteristics of tunnel construction and the requirements of relevant assessment guidelines, the risk levels of tunnel construction indicators are divided into four levels, creating comment set:

$V=\left(V_{1}, V_{2}, V_{3}, V_{4}\right)$

The definition of risk level is shown in Tab. 2 .

\begin{tabular}{|c|c|l|}
\hline \multicolumn{2}{|c|}{ Table 2 Risk level description } \\
\hline Grade & $\begin{array}{c}\text { Comment } \\
\text { collection }\end{array}$ & \multicolumn{1}{c|}{ Grade definition } \\
\hline$V 1$ & Low risk & $\begin{array}{l}\text { The risk can be ignored and no control } \\
\text { measures are required }\end{array}$ \\
\hline$V 2$ & Medium risk & $\begin{array}{l}\text { Risks are undesirable and need to } \\
\text { strengthen supervision and management }\end{array}$ \\
\hline$V 3$ & High risk & $\begin{array}{l}\text { Risk is undesirable and must be controlled } \\
\text { within a reasonable range }\end{array}$ \\
\hline$V 4$ & Very high risk & $\begin{array}{l}\text { The risk is unacceptable, and certain } \\
\text { improved control measures must be } \\
\text { implemented for the risk }\end{array}$ \\
\hline
\end{tabular}

In the evaluation index system shown in Tab. 1, the magnitudes and dimensions of different indexes are quite different and unable to calculate uniformly. Therefore, the evaluation index is quantified to $[0,10]$, and divided into 4 levels according to the evaluation set. The specific quantification standard of the evaluation index is shown in Tab. 3. 
Table 3 Quantification Standard of Evaluation Index

\begin{tabular}{|c|c|c|c|c|}
\hline \multirow{2}{*}{ Evaluation index } & \multicolumn{4}{|c|}{ Quantitative score } \\
\hline & $0 \sim 3\left(V_{1}\right)$ & $3 \sim 5\left(V_{2}\right)$ & $5 \sim 7\left(V_{3}\right)$ & $7 \sim 10\left(V_{4}\right)$ \\
\hline Basic quality grade of rock mass & I, II & III & IV & $\mathrm{V}$ \\
\hline $\begin{array}{l}\text { Underground seepage volume } \\
1 \times(\min \times 10 \mathrm{~m})^{-1}\end{array}$ & $25 \sim 50$ & $50 \sim 100$ & $100 \sim 125$ & $\geq 125$ \\
\hline Degree of rock weathering & unweathered & medium weathered & strong weathered & fully weathered \\
\hline Fracture condition of fault $/ \mathrm{m}$ & $<10$ & $10 \sim 30$ & $30 \sim 50$ & $\geq 50$ \\
\hline Earthquake intensity, & $\mathrm{I}, \mathrm{II}$ & III, IV & $\mathrm{V}, \mathrm{VI}$ & VII \\
\hline Annual rainfall $/ \mathrm{mm}$ & $<400$ & $400 \sim 800$ & $800 \sim 1600$ & $\geq 1600$ \\
\hline Tunnel buried depth / $\mathrm{m}$ & $<10$ & $10 \sim 40$ & $40 \sim 60$ & $\geq 60$ \\
\hline Span $/ \mathrm{m}$ & $<9$ & $9 \sim 14$ & $14 \sim 18$ & $\geq 18$ \\
\hline Monitoring measurement plan & $\begin{array}{l}\text { The frequency is more } \\
\text { reasonable }\end{array}$ & the frequency is reasonable & the frequency is low & the frequency is very low \\
\hline Emergency rescue level & good & fair & poor & very poor \\
\hline Disturbance of surrounding rock & no disturbance & micro disturbance & disturbance & severe disturbance \\
\hline Effect of the support scheme & Good & Generally good & Poor & Worse \\
\hline
\end{tabular}

\subsection{Weight Determination Based on the Combination Weighting Method}

\subsubsection{AHP}

The analytic hierarchy process is a method of subjective weighting obtained by experts based on empirical judgments. It decomposes complex issues into a hierarchical structure and uses a judgment matrix to analyze the importance of various factors. The core idea is to assess the importance of each factor based on the expert's experience. The judgment matrix of the indicator is scored to obtain the attribute weight.

1) Construct judgment matrix of criterion layer and calculate the weight. The experts themselves compare the criterion levels and score according to the 1-9 scale method to judge the relative importance of the indicators. The judgment matrix is shown in Eq. (3). The assignment method is shown in Tab. 4.

$$
\boldsymbol{C}=\left(c_{i j}\right)_{n \times n}=\left[\begin{array}{llll}
c_{11} & c_{12} & \cdots & c_{1 n} \\
c_{21} & c_{22} & \cdots & c_{2 n} \\
\vdots & \vdots & & \vdots \\
c_{n 1} & c_{n 1} & \cdots & c_{n n}
\end{array}\right]
$$

where: $c_{i j}$ is the comparison between index $i$ and index $j$, which is the important value of the criterion layer.

Table 4 Analytic Hierarchy Process Evaluation Standard

\begin{tabular}{|c|l|}
\hline Assignment & \multicolumn{1}{c|}{ Difference in importance } \\
\hline 1 & $c_{i}$ is as important as $c_{j}$ \\
\hline 3 & $c_{i}$ is a bit more important than $c_{j}$ \\
\hline 5 & $c_{i}$ is more important than $c_{j}$ \\
\hline 7 & $c_{i}$ is much more important than $c_{j}$ \\
\hline 9 & $c_{i}$ is extremely more important than $c_{j}$ \\
\hline $2,4,6,8$ & the middle value of the above two adjacent judgments \\
\hline
\end{tabular}

2) Calculate the maximum eigenvalue $\lambda_{\max }$ of the judgment matrix $S$ and its corresponding eigenvector and normalize it.

Normalize each column of matrix $\boldsymbol{C}$ :

$a_{i j}=\frac{c_{i j}}{\sum_{i=1}^{n} c_{i j}}$
Using the approximate method of finding the eigenvector of the judgment matrix, add the normalized matrix by row:

$$
\overline{\eta_{i}}=\sum_{j=1}^{n} a_{i j}
$$

The subjective weight of each indicator is:

$$
\eta_{i}=\frac{\overline{\eta_{i}}}{\sum_{i=1}^{n} \overline{\eta_{i}}}
$$

Calculate the largest characteristic:

$$
\lambda_{\max }=\frac{1}{n} \sum_{i=1}^{n} \frac{(C \eta)_{i}}{\eta_{i}}
$$

3) Consistency inspection

In order to avoid the subjective bias of experts and ensure reasonable weight distribution, the consistency of the judgment matrix should be verified. Conformity ratio $C R$ is:

$$
C R=\frac{C I}{R I}
$$

In the formula, $R I$ is the random consistency index of $S, C I$ is the consistency index of $S$, as shown in Eq. (9).

$$
C I=\frac{\lambda_{\max }-n}{n-1}
$$

When $C R=\frac{C I}{R I}<0.1$, the judgment matrix is considered to be consistent and the weights are valid.

\subsubsection{Entropy Method}

Entropy is mainly used to measure uncertainty. The information entropy value of an evaluation indicator is inversely proportional to the amount of information. The smaller the value of information entropy, the greater the amount of information contained in the indicator, and the 
corresponding weight of the indicator is also big. Entropy weight method is an objective weighting method. In the weighting process, with the help of the variation process of the index, the entropy weight is calculated according to the information entropy of the index, and the objective information can be used to calculate the weight to the greatest extent. The calculation process is as follows.

Construct a judgment matrix, set $m$ items to be evaluated, $n$ evaluation indicators to form the original judgment matrix $\boldsymbol{R}=\left(r_{i j}\right)_{m \times n}$, and calculate the entropy value of the No. $j$ indicator is:

$$
\left\{\begin{array}{l}
p_{i j}=\frac{r_{i j}}{\sum_{i=1}^{m} r_{i j}} \\
k=\frac{1}{\ln m} \\
e_{j}=-k \sum_{i=1}^{n} p_{i j} \ln p_{i j}
\end{array}\right.
$$

where $r_{i j}$ is the evaluation value of the No. $i$ item under the No. $j$ index, and $e_{j}$ is the entropy value of the No. $j$ index.

Calculate the entropy weight of the No. $j$ index.

$$
\lambda_{j}=\frac{1-e_{j}}{\sum_{j=1}^{n}\left(1-e_{j}\right)}
$$

\subsubsection{Combination Weighting}

According to the analytic hierarchy process and entropy method, the subjective weight and the objective weight are calculated. Subjective weighting and objective weighting have their own advantages and disadvantages. It is more reasonable to combine the objective internal laws of indicators and the decision-making of expert experience.

From the subjective weight $\eta_{j}$ and the objective weight $\lambda_{j}$ of each evaluation index to solve the combined weight $\omega_{j}$, the spatial distribution of $\omega_{j}$ must be as close as possible to $\lambda_{j}$ nd $\eta_{j}$. According to the principle of minimum information entropy, it can be obtained:

$$
\left\{\begin{array}{l}
\min F=\sum_{j=1}^{m} \omega_{j}\left(\ln \omega_{j}-\ln \lambda_{j}\right)+\sum_{j=1}^{m} \omega_{j}\left(\ln \omega_{j}-\ln \eta_{j}\right) \\
\sum_{j=1}^{m} \omega_{j}=1\left(\omega_{j}>0, j=1,2, \ldots, m\right)
\end{array}\right.
$$

Solve the optimization problem according to the Lagrangian multiplier method and get the comprehensive weight:

$$
\omega_{i}=\frac{\sqrt{\lambda_{i} \eta_{i}}}{\sum_{i=1}^{m} \sqrt{\lambda_{i} \eta_{i}}}
$$

\subsection{Risk Cloud}

Experts are invited to quantify the 12 secondary evaluation indicators with reference to the quantification standards in Tab. 1, and score each evaluation indicator with a precision of 0.1 . The inverse cloud generator is used to generate the three characteristic numbers of the secondary sub-risk cloud, which are recorded as $R_{i j}=\left(E x_{i}\right.$, $\left.E n_{i}, H e_{i}\right)$.

$$
\left\{\begin{array}{l}
E x=\sum_{i=1}^{n} \omega_{i} \times E x_{i} \\
E n=\sum_{i=1}^{n} \omega_{i} \times E n_{i} \\
H e=\sum_{i=1}^{n} \omega_{i} \times H e_{i}
\end{array}\right.
$$

where $E x_{i}, E n_{i}, H e_{i}$ are the expectation, entropy, and superentropy of the first-level index $U_{i}$ risk cloud, respectively; $E x_{i j}, E n_{i j}, H e_{i j}$ are the expectation, entropy, and superentropy of the second-level $U_{i j}$ risk cloud respectively.

\subsection{Standard Cloud}

The cloud model is used to describe the four evaluation criteria of the tunnel construction risk comment set, where the No. $j$ subinterval is expressed as $\left[C_{\min }^{j}, C_{\max }^{j}\right]$, and the standard cloud inverse generator is used to generate the standard cloud characteristic number $S=(E x, E n, H e)$, standard Cloud digital features are calculated as follows:

$$
\left\{\begin{array}{l}
E x=\left(C_{\text {min }}+C_{\text {max }}\right) / 2 \\
E n=\left(C_{\text {max }}+C_{\text {min }}\right) / 6 \\
H e=k
\end{array}\right.
$$

where, Ex,En, He are the expectation, entropy, and excess entropy of the standard cloud, respectively; $k$ reflects the randomness of subjective evaluation, and the value should not be too large, and $k=0.1$.

The digital characteristics of the standard cloud are shown in Tab. 5, and the standard cloud is shown in Fig. 2.

Table 5 Standard cloud digital characteristics

\begin{tabular}{|l|c|c|}
\hline \multicolumn{1}{|c|}{ Evaluation grade } & Score & Standard cloud digital features \\
\hline Low risk $\left(V_{1}\right)$ & $(0,3)$ & $(1.5,0.5,0.1)$ \\
\hline Medium risk $\left(V_{2}\right)$ & $(3,5)$ & $(4.0,0.33,0.1)$ \\
\hline High risk $\left(V_{3}\right)$ & $(5,7)$ & $(6.0,0.33,0.1)$ \\
\hline Very high risk $\left(V_{4}\right)$ & $(7,10)$ & $(8.5,0.5,0.1)$ \\
\hline
\end{tabular}

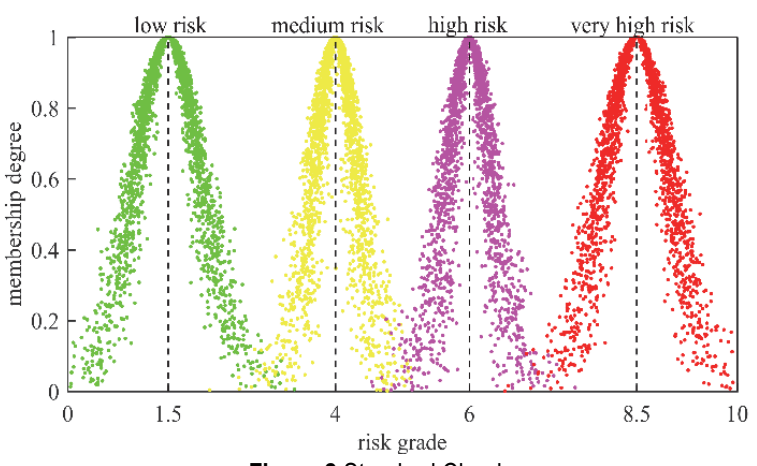

Figure 2 Standard Cloud 


\subsection{Risk Cloud Picture}

Use Matlab to program the forward cloud generator to generate standard cloud diagrams and risk cloud diagrams. Observe the position and shape of the risk cloud to determine the risk status of the evaluation object. It is expected that $E x$ falls within a certain standard cloud interval, and the risk level is the standard cloud level; the greater the entropy $E n$ and the hyper-entropy $H e$, the greater the span of the risk cloud, the thicker the cloud, and the greater the dispersion and randomness of the evaluation index.

\section{ENGINEERING APPLICATIONS 4.1 Engineering Background}

Deda Tunnel is located in the hinterland of western Sichuan Plateau and Ganzi Tibetan Autonomous Prefecture of Sichuan province. It is adjacent to Heni Township of Litang County in the east, Deda Township of Batang County in the west, and Bogoxi Township of Batang County in the south. The average annual precipitation in this region is about $1000 \sim 1200 \mathrm{~mm}$, mostly in June September. The entry mileage pile number of Deda Tunnel is CK603 +250 , the exit mileage pile number is CK636 +280, and the center mileage pile number is CK619 +765. The length of the tunnel is $33030 \mathrm{~m}$, which is in human slope, and the maximum buried depth is about $1230 \mathrm{~m}$. Most of the tunnel trunk is yanshanianmonzo granite and syenogranite. Fault breccia, cataclastic rock and fault gouge are developed in the tensional brittle fault zone, with width ranging from 2 to 10 meters. The tunnel is located in the Yidun-Shaluli late Triassic island arc belt between jinsha River suture zone and Litang suture zone, with 17 large fractures. We assess the construction risk of a section of the Deda tunnel. The segment of tunnel crossing the fault fracture zone, the grade of surrounding rock to III area drainage tunnel site of jinsha river tributary stream. The groundwater types are as follows: the groundwater is dominated by structural fissure water and carbonate karst erosion fissure water; the second is fissure water in weathered zone network; and the distribution of pore water is limited. Through comprehensive analysis, the normal water inflow of the tunnel was predicted to be $114.669 \mathrm{~m}^{3} / \mathrm{d}$, and the maximum water inflow in the wet period was $172.003 \mathrm{~m}^{3} / \mathrm{d}$. The ground motion peak acceleration of $0.20 \cdot \mathrm{g}$, the ground motion response spectrum feature period of $0.40 \mathrm{~s}$, its corresponding basic earthquake intensity is VIII degrees. The geological environment of Deda tunnel is very complex, which has great influence on tunnel construction.

\subsection{Data Processing}

We invited 8 experts with rich experience in construction risk management to quantify the evaluation index system, and the specific quantitative scores are shown in Tab. 6.

Table 6 Evaluationindex score

\begin{tabular}{|c|c|c|c|c|c|c|c|c|c|c|}
\hline TT1: & & & & & & & & & & \\
\hline \multirow{13}{*}{$U$} & First grade indexes & Second grade indexes & $x_{1}$ & $x_{2}$ & $x_{3}$ & $x_{4}$ & $x_{5}$ & $x_{6}$ & $x_{7}$ & $x_{8}$ \\
\hline & \multirow{4}{*}{$U_{1}$} & $U_{11}$ & 3.5 & 4 & 4.5 & 5 & 3.5 & 4.8 & 5 & 5 \\
\hline & & $U_{12}$ & 3.4 & 4 & 4.8 & 5 & 3.8 & 4.7 & 5 & 5 \\
\hline & & $U_{13}$ & 5.8 & 6 & 6.4 & 6.6 & 6.5 & 6 & 5.5 & 6 \\
\hline & & $U_{14}$ & 5.9 & 6.2 & 6.5 & 6 & 6 & 6.5 & 6.6 & 5.5 \\
\hline & \multirow{2}{*}{$U_{2}$} & $U_{21}$ & 8 & 8.5 & 9 & 10 & 9.5 & 9 & 8.5 & 10 \\
\hline & & $U_{22}$ & 5.8 & 6 & 6.5 & 6 & 5.5 & 6.8 & 7 & 6 \\
\hline & \multirow{2}{*}{$U_{3}$} & $U_{31}$ & 8 & 9 & 9.5 & 9 & 8.8 & 9 & 10 & 9.5 \\
\hline & & $U_{32}$ & 8.5 & 9 & 9.2 & 9 & 8.5 & 9 & 9.5 & 10 \\
\hline & \multirow{4}{*}{$U_{4}$} & $U_{41}$ & 2 & 1.5 & 1 & 2 & 2.5 & 2.8 & 3 & 2.5 \\
\hline & & $U_{42}$ & 5 & 4.5 & 5 & 5.5 & 6 & 4.5 & 4.8 & 3.5 \\
\hline & & $U_{43}$ & 3 & 3.5 & 3 & 2.8 & 3 & 2.5 & 3 & 3.5 \\
\hline & & $U_{44}$ & 2 & 2 & 1.5 & 2.5 & 2.5 & 2.6 & 2.6 & 3 \\
\hline
\end{tabular}

In order to improve the rationality of index weight calculation, the combination weighting method is used to calculate the weight. The analytic hierarchy process is used to calculate the subjective weight of each index. Entropy weight method is used to calculate the objective weight of each index. The comprehensive weight obtained from Eq. (13) is shown in Tab. 7 and Tab. 8.

Table 7 First grade indexes weight

\begin{tabular}{|c|c|c|c|}
\hline $\begin{array}{c}\text { First grade } \\
\text { indexes }\end{array}$ & $\begin{array}{c}\text { Subjective } \\
\text { weight }\end{array}$ & $\begin{array}{c}\text { Objective } \\
\text { weight }\end{array}$ & $\begin{array}{c}\text { Comprehensive } \\
\text { weight }\end{array}$ \\
\hline$U_{1}$ & 0.38 & 0.32 & 0.38 \\
\hline$U_{2}$ & 0.12 & 0.17 & 0.12 \\
\hline$U_{3}$ & 0.25 & 0.16 & 0.15 \\
\hline$U_{4}$ & 0.24 & 0.37 & 0.35 \\
\hline
\end{tabular}

Applying the reverse cloud generator to process the quantization value of the second-level evaluation index, the second-level sub-risk cloud is obtained. Eq. (14) is applied for calculation to obtain the digital characteristics of the first-level sub-risk cloud, and then the digital characteristics of the comprehensive risk cloud. The specific results are shown in Tab. 9.

Table 8 Second grade indexes

\begin{tabular}{|c|c|c|c|}
\hline $\begin{array}{c}\text { Second grade } \\
\text { indexes }\end{array}$ & $\begin{array}{c}\text { Subjective } \\
\text { weight }\end{array}$ & $\begin{array}{c}\text { Objective } \\
\text { weight }\end{array}$ & $\begin{array}{c}\text { Comprehensive } \\
\text { weight }\end{array}$ \\
\hline$U_{11}$ & 0.425 & 0.285 & 0.516 \\
\hline$U_{12}$ & 0.352 & 0.316 & 0.277 \\
\hline$U_{13}$ & 0.220 & 0.195 & 0.135 \\
\hline$U_{14}$ & 0.100 & 0.152 & 0.072 \\
\hline$U_{21}$ & 0.710 & 0.518 & 0.656 \\
\hline$U_{22}$ & 0.415 & 0.355 & 0.344 \\
\hline$U_{31}$ & 0.680 & 0.515 & 0.628 \\
\hline$U_{32}$ & 0.425 & 0.386 & 0.372 \\
\hline$U_{41}$ & 0.324 & 0.258 & 0.323 \\
\hline$U_{42}$ & 0.300 & 0.200 & 0.240 \\
\hline$U_{43}$ & 0.256 & 0.148 & 0.165 \\
\hline$U_{44}$ & 0.255 & 0.245 & 0.272 \\
\hline
\end{tabular}

The forward cloud generator is applied to generate a comparison diagram of comprehensive risk cloud and standard cloud, as shown in Fig. 3. In order to observe the 
risk state of the first-level index tunnel engineering design scheme, a comparison diagram of $U_{3}$ risk cloud and standard cloud is generated, as shown in Fig. 4. To observe the seismic intensity risk status of the second-level index layer, a comparison chart of $U_{21}$ risk cloud and standard cloud is generated, as shown in Fig. 5.

Table 9 Evaluation index risk cloud digital characteristics

\begin{tabular}{|c|c|c|c|c|c|}
\hline $\begin{array}{c}\text { Overall } \\
\text { performance }\end{array}$ & $\begin{array}{l}\text { Integrated risk } \\
\text { cloud }\end{array}$ & First grade indexes & $\begin{array}{l}\text { First level risk } \\
\text { cloud }\end{array}$ & Second grade indexes & Second level risk cloud \\
\hline \multirow{12}{*}{$\begin{array}{c}\text { tunnel } \\
\text { construction } \\
\text { risk assessment } \\
\text { system U }\end{array}$} & \multirow{12}{*}{$(5.18,0.4,0.08)$} & \multirow{4}{*}{ engineering geology $U_{1}$} & \multirow{4}{*}{$(4.80,0.45,0.07)$} & rock mass grade $U_{11}$ & $(4.41,0.50,0.08)$ \\
\hline & & & & subsurface seepage $U_{12}$ & $(4.52,0.61,0.09)$ \\
\hline & & & & degree of rock weathering $U_{13}$ & $(6.12,0.26,0.04)$ \\
\hline & & & & fault fracture zone $U_{14}$ & $(6.22,0.27,0.06)$ \\
\hline & & \multirow{2}{*}{ natural environment $U_{2}$} & \multirow{2}{*}{$(8.11,0.44,0.11)$} & earthquake intensity $U_{21}$ & $(9.12,0.53,0.12)$ \\
\hline & & & & annual precipitation $U_{22}$ & $(6.20,0.28,0.09)$ \\
\hline & & \multirow{2}{*}{$\begin{array}{l}\text { tunnel engineering } \\
\text { design scheme } U_{3}\end{array}$} & \multirow{2}{*}{$(9.07,0.35,0.12)$} & tunnel depth $U_{31}$ & $(9.11,0.38,0.14)$ \\
\hline & & & & tunnel span $U_{32}$ & $(9.00,0.30,0.08)$ \\
\hline & & \multirow{4}{*}{$\begin{array}{c}\text { construction } \\
\text { management and } \\
\text { technology } U_{4}\end{array}$} & \multirow{4}{*}{$(3.16,0.37,0.06)$} & monitoring measurement scheme $U_{41}$ & $(2.22,0.47,0.06)$ \\
\hline & & & & Emergency rescue level $U_{42}$ & $(4.82,0.36,0.05)$ \\
\hline & & & & Disturbance of surrounding rock $U_{43}$ & $(3.81,0.28,0.06)$ \\
\hline & & & & Effect of the support scheme $U_{44}$ & $(2.43,0.34,0.05)$ \\
\hline
\end{tabular}

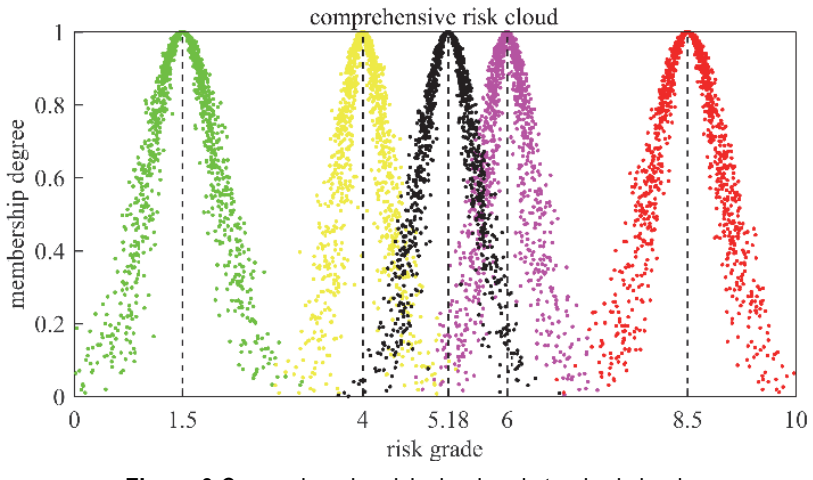

Figure 3 Comprehensive risk cloud and standard cloud

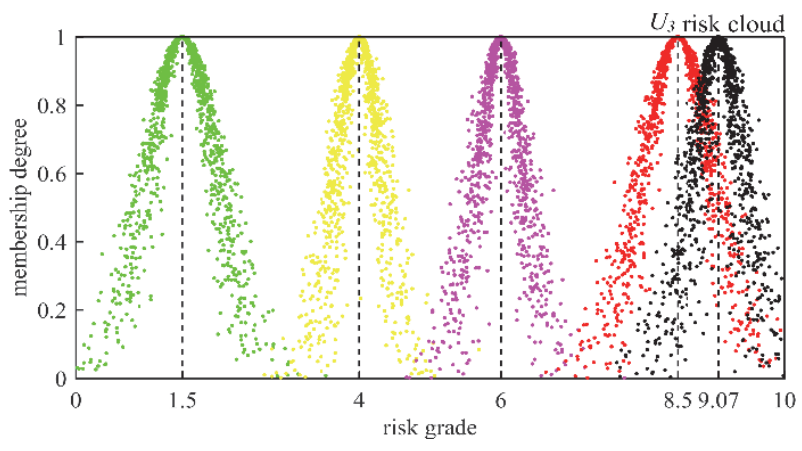

Figure $4 U_{3}$ Risk cloud and standard cloud

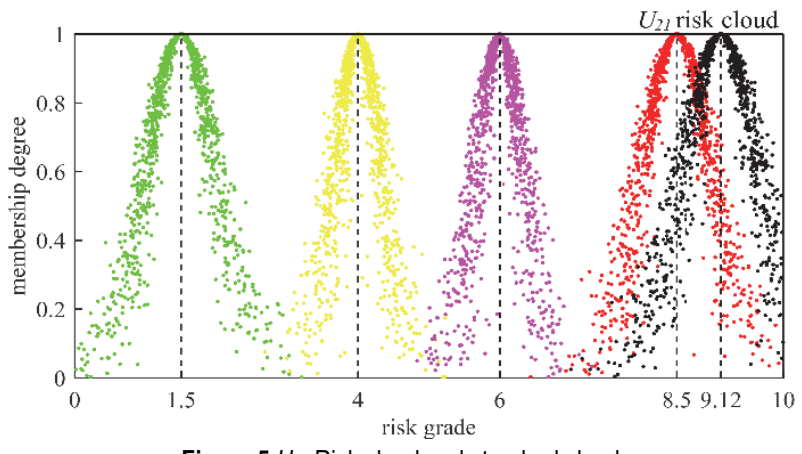

Figure $5 U_{21}$ Risk cloud and standard cloud

\subsection{Assessment Results Analysis}

As can be seen from Fig. 3, the comprehensive risk level of Deda tunnel construction is high and the risk is unacceptable, so management and decision should be made to avoid the risk. According to the comprehensive analysis shown in Fig. 4 and Fig. 5, the seismic condition risk level of the tunnel is ultra-high, and the buried depth risk and span risk level of the tunnel engineering design scheme are ultra-high. Deda tunnel is located in the seismically active area, and the secondary geological disasters caused by high intensity earthquake, such as rock fall, collapse, landslide and debris flow, may constitute a major hazard to the safety of tunnel construction. For the seismically active and strong, the construction of Deda tunnel should be increased to meet the seismic requirements. The Deda tunnel is located in the hinterland of the Western Sichuan Plateau, with complicated geological conditions and great topographic difference, which increases the difficulty and requirements of the tunnel design scheme, and the construction of the tunnel with large burial depth and span and the health security of the construction personnel are all faced with extremely high risks. Therefore, we suggest that construction units should attach importance to the safety supervision of the construction of tunnels. As for possible accidents, relevant emergency units should start the emergency plan as soon as possible, take safety protection measures, reduce the working time in areas with frequent geological activities as much as possible, and do a good job in the construction risk management and control.

\section{CONCLUSION}

(1) According to the characteristics of tunnel construction, a tunnel construction risk assessment index system is constructed, which includes four first-grade indexes including engineering geology, natural environmental conditions, tunnel engineering design scheme and construction management, and 12 secondgrade indexes. The randomness and fuzziness of evaluation indexes are treated synthetically by cloud model theory, and the transformation between qualitative concept and quantitative expression of security level is realized.

(2) Based on cloud model theory, this paper proposes a risk assessment method for tunnel construction. The cloud model evaluation results are presented in the form of contrast cloud picture to intuitively reflect the risk status of tunnel construction. The weight calculation method based on AHP, entropy weight method and Lagrange multiplier method, achieves the comprehensiveness of calculating the 
weight of the tunnel construction evaluation index, and improves the reliability of the model.

(3) This paper applies cloud model to evaluate the construction risk of a section of Deda tunnel of SichuanTibet Railway and the evaluation results are in agreement with the engineering practice. It proves that the method is accurate and can be operated, which has certain reference value for the research of tunnel construction risk assessment.

\section{Acknowledgements}

The present work was supported by National Natural Science Foundation of China (Grant No. 71941014) and Key R\&D Project of Hebei Province of China (Grant No. 19275410D). The financial supports are gratefully acknowledged.

\section{REFERENCES}

[1] Xue, Y. G., Kong, F. M., Yang, W. et al. (2020). Main unfavorable geological conditions and engineering geological problems along Sichuan Tibet railway. Chinese Journal of Rock Mechanics and Engineering, 39(03), 445468.

[2] Xu, Y. K. \& Yao, L. K. (2017). Some Cognitions and Thinkings about the Specific Geo-environmental Problems along the Sichuan-Tibet Railway. Journal of Railway Engineering Society, 34(01), 1-5.

[3] Lu, C. F. \& Cai, C. X. (2019). Challenges and Countermeasures for Construction Safety during the Sichuan-Tibet Railway Project. Engineering, 5(05), 49-61. https://doi.org/10.1016/j.eng.2019.06.007

[4] Sorrill, C. M. (1987). Risk analysis for large projects: models, methods and cases. Journal of the Operational Research Society, 38(12), 1217-1219. https://doi.org/10.2307/2582754

[5] Einstein, H. H. (1996).Risk and risk analysis in rock engineering. Tunneling and Underground Technology, 11(2), 14. https://doi.org/10.1016/0886-7798(96)00014-4

[6] Khakzad, N., Khan, F., \& Paltrinieri, N. (2014). On the application of near accident data to risk analysis of major accidents. Reliability engineering \& system safety, 126(6), 116-125. https://doi.org/10.1016/j.ress.2014.01.015

[7] Hyun, K.-C., Sangyoon, C. et al. (2015). Risk analysis using fault-tree analysis (FTA) and analytic hierarchy process (AHP) applicable to shield TBM tunnels. Tunnelling and underground space technology, 49(6), 121-129. https://doi.org/10.1016/j.tust.2015.04.007

[8] Bejari, H., Shahriar, K., Rostami, J. et al. (2010). Risk assessment based selection of rock TBM for adverse geological conditions using Fuzzy-AHP. Bulletin of engineering geology and the environment, 69(4), 523-532. https://doi.org/10.1007/s10064-009-0260-8

[9] Marian, W., Grzyl, B. et al. (2017). Risk Modelling with Bayesian Networks - Case Study: Construction of Tunnel under the Dead Vistula River in Gdansk. Procedia Engineering, 196. https://doi.org/10.1016/j.proeng.2017.08.046

[10] Andreotti, G. \& Lai, C. G. (2019). Use of fragility curves to assess the seismic vulnerability in the risk analysis of mountain tunnels. Tunnelling and Underground Space Technology incorporating Trenchless Technology Research, 91. https://doi.org/10.1016/j.tust.2019.103008

[11] Bjelland, H. \& Aven, T. (2013). Treatment of uncertainty in risk assessments in the Rogfast road tunnel project. Safety Science, 55. https://doi.org/10.1016/j.ssci.2012.12.012

[12] Julie, A. Clarke, D., \& Laefer, F. (2014). Evaluation of risk assessment procedures for buildings adjacent to tunnelling works. Tunnelling and underground space technology, 40(2), 333-342. https://doi.org/10.1016/j.tust.2013.10.014

[13] McFeat-Smith， I. \& Harman, K. W. (2004). IMS risk evaluation system for financing and insuring tunnel projects. Tunnelling and Underground Space Technology incorporating Trenchless Technology Research, 19(4). https://doi.org/10.1016/j.tust.2004.01.030

[14] Nezarat, A. et al. (2015). Ranking of geological risks in mechanized tunneling by using Fuzzy Analytical Hierarchy Process (FAHP). Tunnelling and underground space technology, 50(8), 358-364. https://doi.org/10.1016/j.tust.2015.07.019

[15] Audun, B., Henrik, B. et al. (2014). Reflections on Bayesian Network models for road tunnel safety design: A case study from Norway. Tunnelling and Underground Space Technology incorporating Trenchless Technology Research, 43. https://doi.org/10.1016/j.tust.2014.05.004

[16] Zhang, L. M., Wu, X, G., \& Miroslaw, J. (2014). Bayesiannetwork-based safety risk analysis in construction projects. Reliability Engineering and System Safety, 131. https://doi.org/10.1016/j.ress.2014.06.006

[17] Zhang, L. M., Wu, X. G., \& Qin, Y. W. (2016). Towards a Fuzzy Bayesian Network Based Approach for Safety Risk Analysis of Tunnel-Induced Pipeline Damage. Risk analysis: an official publication of the Society for Risk Analysis, 36(2), 278-301. https://doi.org/10.1111/risa.12448

[18] Li, J., Patrick, X. W. et al. (2011). Fuzzy AHP-Based Risk Assessment Methodology for PPP Projects. Journal of construction engineering and management, 137(12), 12051209. https://doi.org/10.1061/(ASCE)C0.1943-7862.0000362

[19] Hyun, K.-C. et al. (2015). Risk analysis using fault-tree analysis (FTA) and analytic hierarchy process (AHP) applicable to shield TBM tunnels. Tunnelling and underground space technology, 49(6), 121-129. https://doi.org/10.1016/j.tust.2015.04.007

[20] Yao, J. P., Wang, G. Q., Xue, B. L. et al. (2019). Assessment of lake eutrophication using a novel multidimensional similarity cloud model. Journal of Environmental Management, 248 . https://doi.org/10.1016/j.jenvman.2019.109259

[21] Liu, Q., Wang, M., Wang, X. et al. (2018). Land EcoSecurity Assessment Based on the Multi-Dimensional Connection Cloud Model. Sustainability, 10(6), 2096. https://doi.org/10.3390/su10062096

[22] Huang, Q., Xu, X., Sun, H. et al. (2018). Condition Assessment of Suspension Bridges Using Local Variable Weight and Normal Cloud Model. KSCE journal of civil engineering, 22(10), 4064-4072. https://doi.org/10.1007/s12205-018-1819-3

[23] Wu, H., Zhen, J., \& Zhang, J. (2020). Urban rail transit operation safety evaluation based on an improved CRITIC method and cloud model. Journal of Rail Transport Planning \&amp; Management, 20(6). https://doi.org/10.1016/j.jrtpm.2020.100206

[24] Wang, D., Liu, D., Ding, H. et al. (2016).A cloud modelbased approach for water quality assessment. Environmental Research, Section A, 148, 24-35. https://doi.org/10.1016/j.envres.2016.03.005

[25] Ma, X., Xue, Y., Wang, X. et al. (2017). Risk Assessment of Rockfall Hazards in a Tunnel Portal Section Based on Normal Cloud Model. Polish Journal of Environmental Studies, 26(5), 2295-2306. https://doi.org/10.15244/pjoes/68427

[26] Wang, G., Xu, C., \& Li, D. (2014). Generic normal cloud model. Information Sciences: An International Journal, 280, 1-15. https://doi.org/10.1016/j.ins.2014.04.051

[27] Yang, J., Liu, H., Yu, X. et al. (2016). Entropy-Cloud Model of Heavy Metals Pollution Assessment in Farmland Soils of Mining Areas. Polish Journal of Environmental Studies, 25(3), 1315-1322. https://doi.org/10.15244/pjoes/61883 


\section{Contact information:}

Jing-chun WANG, Professor

(Corresponding author)

College of Civil Engineering,

Shijiazhuang TieDao University (STDU),

17 Northeast, Second Inner Ring,

Shijiazhuang, Hebei, China

E-mail: wjc36295@163.com

Jia-qi LIU, Master

College of Civil Engineering,

Shijiazhuang TieDao University (STDU),

17 Northeast, Second Inner Ring,

Shijiazhuang, Hebei, China

E-mail: 1849568695@qq.com

Qiang WEI, Professorate Senior Engineer

China Railway Construction Management Co. Ltd.,

Beijing, China

E-mail:wq3537@163.com

Peng WANG, Senior Engineer

China Railway Construction Management Co. Ltd.,

Beijing, China

E-mail: 13911180152@139.com 